
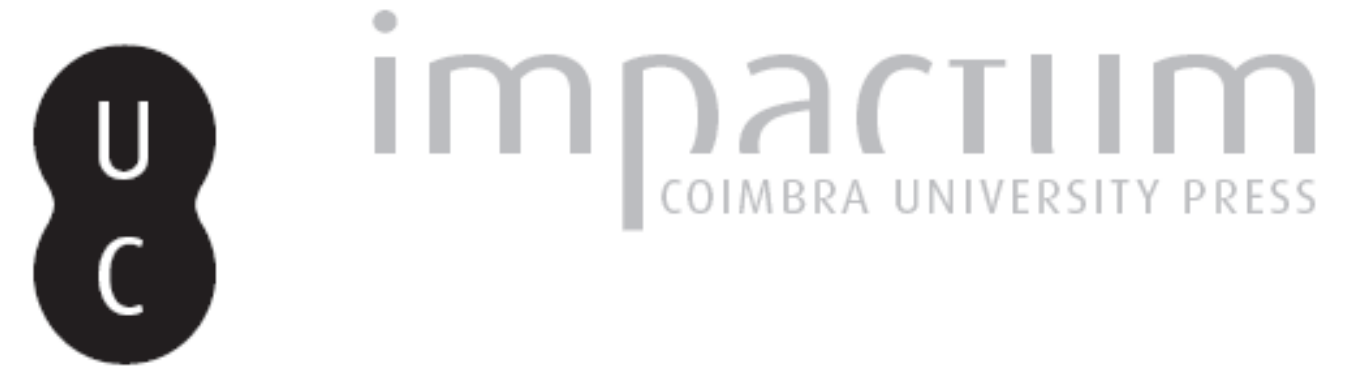

\title{
Uma homenagem a Agripina: mulher de Germânico
}
Autor(es):
D'Encarnação, José

Publicado por: Imprensa da Universidade de Coimbra

URL persistente:

URI:http://hdl.handle.net/10316.2/45572

DOI:

DOI:https://dx.doi.org/10.14195/1647-8657_28_8

Accessed : $\quad$ 26-Apr-2023 15:32:09

A navegação consulta e descarregamento dos títulos inseridos nas Bibliotecas Digitais UC Digitalis, UC Pombalina e UC Impactum, pressupõem a aceitação plena e sem reservas dos Termos e Condições de Uso destas Bibliotecas Digitais, disponíveis em https://digitalis.uc.pt/pt-pt/termos.

Conforme exposto nos referidos Termos e Condições de Uso, o descarregamento de títulos de acesso restrito requer uma licença válida de autorização devendo o utilizador aceder ao(s) documento(s) a partir de um endereço de IP da instituição detentora da supramencionada licença.

Ao utilizador é apenas permitido o descarregamento para uso pessoal, pelo que o emprego do(s) título(s) descarregado(s) para outro fim, designadamente comercial, carece de autorização do respetivo autor ou editor da obra.

Na medida em que todas as obras da UC Digitalis se encontram protegidas pelo Código do Direito de Autor e Direitos Conexos e demais legislação aplicável, toda a cópia, parcial ou total, deste documento, nos casos em que é legalmente admitida, deverá conter ou fazer-se acompanhar por este aviso.

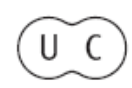


FACULDADE DE LETRAS

INSTITUTO DE ARQUEOLOGIA

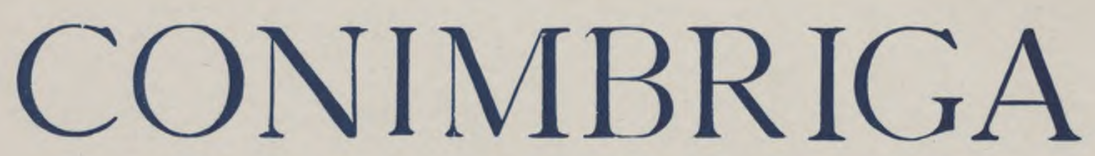

VOLUME XXVIII

UNIVERSIDADE DE COIMBRA

1989 
José D'ENCARNAÇÂO

Professor associado da Faculdade de Letras de Coimbra

UMA HOMENAGEM A AGRIPINA, MULHER DE GERMÂNICO

«Conimbriga», XXVIII (1989), p. 157-167

RESU Mo: Procede-se à revisão da inscrição CIL II 963, dedicada não a

Agripina Minor (como, de um modo geral, se considerou até ao presente) mas sim a Agripina Maior. O texto data do ano $37 \mathrm{e}$ integra-se no amplo movimento de reabilitação dos seus familiares, designadamente seu pai Germânico e sua mãe Agripina, empreendido pelo imperador Caligula nos primeiros tempos do seu reinado. É nesse movimento que se integrará também o iusiurandum Aritiensium (CIL II 172, IRCP 647). O facto de Agripina se identificar como Augusti nepos reforça a ligação que Caligula desejava mostrar com o fundador do Império.

RÉSUMÉ: En procédant à la révision de CIL II 963, l'Auteur considère que l'hommage est fait non à Agripina Minor (comme, d'une façon générale, on le pensait dans la suite de Hübner) mais à Agripina Maior, mère de l'empereur Caligula. Le texte date de l'an 37 et il doit être intégré dans le mouvement général mis en oeuvre par l'initiative de l'empereur Caligula pour la réhabilitation de sa famille, notamment de son père Germanicus et de sa mère Agripina, au début de son gouvernement. L'iusiurandum Aritiensium (CIL II $172=$ IRCP 647) correspond lui aussi à cette intention. Agripina se dit Augusti nepos, ce qui rappelle les liens avec l'empereur Auguste, dont Caligula voulait bien se présenter comme légitime successeur. 
(Página deixada propositadamente em branco) 


\section{UMA HOMENAGEM A AGRIPINA, MULHER DE GERMÂNICO}

Guarda-se no museu municipal de Moura (N. ${ }^{\circ}$ de inventário: 177/EPI 7, n. ${ }^{\circ} 19$ do núcleo romano) um cipo de mármore azulado com venulações brancas, paralelepipédico, alisado nas seis faces, com 92 centímetros de altura, 57 de largura e 52 de espessura. Não existe, na parte superior, qualquer indício que leve a pensar na possibilidade de ter servido como pedestal de estátua. Ostenta na face dianteira, hoje bastante corroída por efeito da exposição secular aos agentes atmosféricos (esteve embutido numa parede), uma inscrição honorífica.

Esta é já conhecida de há muito tempo (cfr., por exemplo, Resende, ${ }^{2} 1790$, f. 171-172), mas talvez não seja descabido proceder a uma revisão da interpretação que the tem sido dada, procurando-se, ao mesmo tempo, integrá-la numa política geral do Império ao tempo em que foi gravada.

Antes de mais, importa salientar que se trata de um cipo e não de uma placa, como a circunstância de ter estar metida na parede levou a pensar. É, portanto, um monumento destinado a figurar solenemente no fórum da civitas Aruccitana.

Quanto ao seu texto, os dois principais pontos a rever dizem respeito ao desdobramento da sigla $\mathrm{N}$ que figura no final da $1.3 \mathrm{e}$ à identificação do imperador referido na 1.2.

\section{A interpretação da epígrafe}

André de Resende faz o desdobramento da sigla em NOVA, ligando esse adjectivo à expressão Civitas Aruccitana da última linha. Nessa ordem de ideias, a homenagem teria sido feita por 
uma Nova Civitas Ameritaría, eventualmente iden ificável com a Moura actual $\left({ }^{1}\right)$. A proposta foi aceite, por exemplo, por Fragoso de Lima (1988, 70-71).

Outra corrente optou por ver ai um adjectivo possessivo $\mathrm{N}$ (ostrae) ou $\mathrm{N}$ (ostri) — de modo que o vocábulo anterior se interpretou, em consequência, $A N Q$ (ustae) ou AVG(usti) a homenageada seria, assim, «a nossa Augusta», ou a mãe «do nosso Augusto».

Dado que se tratava de Júlia Agripina (1. 1), o imperador referido não poderia deixar de ser Nero, porque, de facto, só Agripina, a Nova, se identificava assim.

Vejamos, pois, o que uma análise mais cuidadosa do monumento nos poderá trazer de esclarecedor.

$\mathrm{Na}$ verdade, não se pode admitir o desdobramento do $\mathrm{N}$ em N(oca), como queriam André de Resende e Fragoso de Lima, inclusive por razões de paginação : se a palavra se referisse a civitas deveria ter sido posta na última linha e não a seguir a AVG na linha anterior. Num texto oficial como este, seria lapso imperdoável do lapicida não colocar numa só linha a identificação do dedicante. Por outro lado, não há qualquer razão para admitirmos a existência de duas «civitates Aruccitanae», quando se sabe que, ao contrário também do que supunha Fragoso de Lima, o monumento proveio, segundo o expresso testemunho de Morales (1791-2, 368), da serra de Aroche e dali é que foi levado para Moura, onde já no séc. xvi, como vimos, é referida a sua presença ${ }^{2}$ ). Há, portanto, apenas uma

$\mathrm{t}^{1}$ ) «Mauram insigne oppidum, Novum fuisse Arucci, ex cippo istius modi, quem ibi legi persuasum habeo» (RESENDE, 1790, f. 171). Ou seja: «Estou persuadido que Moura foi uma fortaleza insigne, Arucci Nova, como se depreende do seguinte cipo que aí li».

(2) Teve o Dr. Santiago Macias, da Câmara de Moura, a amabilidade de me dar a conhecer uma passagem do manuscrito 151 da Biblioteca da Universidade de Coimbra, uma História da Notável Vila de Moura, composta por Luís D'Almeida CABRAL, «vigário da vara da mesma vila», manuscrito datado de 1710, em que, após afirmar que a vila se chamou «a princípio Ar ameia a Nova», explica que a prova disso «nos oferece a inscrição que está em uma pedra de letras latinas, bem formadas, no ângulo da parede da cerca do convento das religiosas do Castelo, que diz: Juliae agripinae Caesaris Neronis Augusti Germanici Matri Augustae nova Civitas Armitana» [sic]. 
Arucci, a única citada pelos autores antigos, nomeadamente pelo Itinerário de Antonino $(427,2)$, que a situa na via de Esuri a Pax Iulia, a vinte milhas de Fines e a trinta de Paxlulia. De acordo com a investigação levada a efeito por Julián González (1988), o local mais provável dessa antiga «civitas Aruccitana» é, não a cidade de Aroche ${ }^{(3)}$, de moderna implantação, mas a zona com ela confinante onde se situa a jazida de Fuente Seca.

$\mathrm{O}$ desdobramento do $\mathrm{N}$ em $\mathrm{N}$ (ostrae) (ILER 1261) ou em $\mathrm{N}$ (ostri) (CIL II 963) também não é aceitável. De facto, este possessivo tem ampla conotação afectiva, sendo usado de preferência em dedicatórias pessoais, designadamente por elementos da familia Caesaris, ou seja, por membros da casa imperial (sobretudo escravos). Em segundo lugar, se se tratasse de Agripina, a Nova, era preciso ter em conta que o título de Augusta, outorgado no ano 37, passou a ser parte integrante da sua identificação nas epígrafes - IVLIA AVG. AGRIPPINA—, pelo que não teria sentido a sua menção no final. Por último, a posposição Augusti Nostri ao vocábulo que a determinava [matri) não seria muito admissível tanto sintáctica como epigraficamente.

A paginação da epígrafe e as letras que restam da linha 2 não permitem, além disso - e este é, sem dúvida, o argumento de maior peso - , que se considere a homenagem feita a Agripina, a Nova, mas sim a Agripina, a Velha, mãe de Caligula. Efectivamente, no começo da 1. 2, os vestígios de letras existentes permitem uma fácil reconstituição da palavra CAESARIS e não há espaço senão para mais uma letra, o $\mathrm{C}$ de $C$ (aii). Temos, por conseguinte, a identificação habitual de Caligula nas inscrições :

\section{C . CAESAR AVG . GERMANICVS}

Compreende-se, desta forma, o polémico $\mathrm{N}$ : trata-se da normal sigla de N(epos) — filha de Júlia, Agripina era, de facto, neta do

(3) «Novum autem Arucci dici puto, quoniam adhuc superest Arucci vetus, nomenque retinet. Vulgo enim Arouche dicitur», escreve ANDRÉ DE RESENDE (ibidem, f. 173): «Penso que se deverá ter designado Nova Arucci porque ainda persiste a antiga Arucci e mantém a designação. Ghama-se, com efeito, vulgarmente Arouche».

Conimbriga, 28 (1989), 157-167 
imperador Augusto, e, segundo informou Silvio Pandera aquando da discussão da citada comunicação de Julián González, há inscrições de Roma onde Agripina se identifica como neta de Augusto.

Uma questão subsiste, justamente aquela que terá levado Hübner a duvidar da atribuição do texto $\left(^{4}\right)$ : é que só Agripina, a Nova, é referida nas inscrições como Iulia Agrippina. Trata-se, na verdade, de uma objecção válida: mas, perante as anomalias de interpretação epigráfica a que essa identificação obrigava, penso que se poderá, sem grande dificuldade, levar o «lapso» à conta de uma «contaminação» com a forma como habitualmente as mulheres se identificam - com gentilicio e cognomen —, num texto em que não havia perigo de se confundirem as duas Agripinas, mãe e filha.

É, por conseguinte, esta a leitura do monumento $\left({ }^{5}\right)$ :

\author{
[IVJLIAE . AGRIPPINA[E] \\ [C.] CAE[SA]RIS . AVG . GERMANfl] \\ ' '[Cl] . MATRI . AVG . N \\ CIVITAS ARVCCITANA
}

$\left.{ }^{4}\right)$ Até agora, as referências à epígrafe têm-se baseado quase exclusi vamente na primeira hipótese de Hübner, sem, inclusive, se reparar na possibilidade, que o epigrafista anota nos índices do CIL II, p. 1097, de se tratar de Agripina, mulher de Germânico. Aliás, sob o n. ${ }^{\circ}$ 963, Hübner, depois de apresentar as versões de Peutinger, Strada, Morales e Resende, sugere que se leia, no fim da 1. 1, a palavra NERONIS, suspeitando que a tivessem martelado, e opta por reconstituir AVG(ícsíae) N(osírae), datando o texto de 54-59. Na versão de Strada, diz ele, uma versão que baralhou as linhas, ainda se poderia conjecturar matri August(i) Caes(aris). Em comentário, T. Mommsen chama a atenção para o carácter insólito do título Augustae nostrae naquela época e prefere considerar a reconstituição matri Aug(usti) nastri), sendo, por isso, o imperador identificado como divi Claudi Caes(aris) Aug[usti) Germani (ci), ou seja, no entender de Mommsen, assinalar-se-ia no monumento a circunstância de Agripina ter sido mulher de Cláudio e mãe de Nero. Essa hipótese foi retomada por Hübner num aditamento (p. LI), seguindo agora a versão transmitida por Langsdorf: o «nosso Augusto» era Nero, assim identificado «imediatamente após a morte de Cláudio». Todas estas conjecturas derivam, pois, de não ter sido possível proceder a uma cuidadosa análise do monumento.

$\left({ }^{5}\right)$ Altura das letras: 1. 1: 5,3; 1. 2: 4; 1. 3: $4(\mathrm{I}=5,3)$; 1. 4: 4. Espaços: $1: 6,5 ; 2: 2 ; 3: 4 ; 4: 2,5 ; 5: 5,9$.

Nal. 1, IV desapareceu com a erosão e o E final na fractura. Na 1. 2, do 
[IVJLIAE (ihedera) AGRIPPINA[E] / [C(aii)] . CAE[SA]RIS \{hedera). AVG(usti). GERMAN[I]/[CI] . MATRI * XVG(usti) . . N (epoti) I CIVITAS ARVCCITANA

A Julia Agripina, mãe de Gaio César Augusto Germânico, neta de Augusto - a cidade Arucitana.

\section{O significado da homenagem}

Há, pois, que interrogarmo-nos acerca do porquê da homenagem, o que equivalerá a responder a duas questões fundamentais :

1 -É única na Península Ibérica?

2 - Integrar-se-á nalguma directriz política específica?

Esta segunda questão prende-se necessariamente com a datação do monumento.

Não é esta a única dedicatória a Agripina conhecida na Península Ibérica. Há, pelo menos, mais duas $\left({ }^{6}\right)$ :

primeiro G nada resta, mas da palavra CAESARIS só de SA não há qualquer vestígio; no final, poderá, como é mais natural, ter sido grafado o I. O começo da 1. 3 está muito erodido e, na 1. 4, apesar de bastante gastas, as letras CIVITAS ainda se distinguem. A pontuação afigura-se triangular, àexcepçãoda hera que existe na 1.1 e duma outra, mais curta, na 1. 2, a preceder AVG. Caracteres actuários (o G enrola para dentro).

A leitura apresentada difere, naturalmente, de todas as que consideravam existir, na 1. 2, o nome de Nero. Aliás, é curioso referir que Resende lê GERMANICI por inteiro nal. 1, põe a hipótese de faltarem letras no começo da 1.3 e dá como estando por extenso na pedra a palavra NOVA.

Trillmich $(1982,120)$ segue Hübner, reconstituindo NERONIS e AVG (ustae) $\mathrm{N}$ (ostrae), mas chega a pôr a hipótese de a epígrafe ser falsa, atendendo inclusive à forma «inusitada» como o imperador viria identificado ; aduz, porém, a esse propósito, a argumentação de Hübner e paralelos verificados em moedas (ibidem, nota 37).

Em relação à proposta de leitura de J. González, as divergências são, apenas, de carácter epigráfico: aquele investigador (que, segundo creio, não viu o monumento) lê $\mathrm{C}\left(\mathrm{a}_{i}\right)$ ainda na 1.1 e a terminação ICI na 1. 2 .

${ }^{6}$ ) Em ILER 1261 apresenta-se, por lapso, Agripina, a Nova, como «esposa de Germânico». Agradeço a José Maria Alvarez Martinez, director do museu de Mérida, as informações que amavelmente me deu acerca de ILER 1259. 
- O Museo Nacional de Arte Romano, de Mérida, guarda urna base (N. ${ }^{\circ}$ inv. $^{\circ}: 141$ ), de mármore, de $38 \mathrm{~cm}$ de alto e $83 \mathrm{~cm}$ de largo e de espessura, onde, em letras «óptimas, de $7 \mathrm{~cm}$ de altura» (para usar a expressão de Hübner em EE Vili 20), apenas se lê AGRIPPINAE (ILER 1259). Nos índices desse seu trabalho (p. 530), aquele investigador alemão anota «incertum utrum maior an minor», com que manifesta, mais uma vez, a sua dúvida quanto à atribuição do letreiro a uma ou a outra das Agripinas, porque a pedra foi cortada ao nível da 1. 2, que aparece picada em virtude de damnatio memoriae. Tanto Caligula como Nero foram amaldiçoados após a morte, mas não será, decerto, ousadia optar por ver aí a base duma estátua ou de um busto a Agripina, a Velha.

- Em Mentesa Bastitanorum (La Guardia), Q. Fábio Hispano, flàmine dos Augustos, promove, por decreto da ordem dos decuriões, uma dedicatória a Agripina, «mãe de C. César Augusto Germânico» (CILII 3379 = ILER 1260).

Ao comentar esta epígrafe, opina R. Étienne $(1974,207)$ que ela se deve localizar cronologicamente entre os anos 37 e 41 e, talvez mesmo de preferência em 37, ano «que vê surgir em Roma e, sem dúvida, pouco depois em Caesaraugusta, uma emissão de denários e de aurei com a legenda AGRIPPINA. MAT. C. CAES. GERM, ou seja, a mesma formula da nossa inscrição», o que significará, segundo acrescenta em nota, que «a amoedação imperial serviu de modelo ao redactor da inscrição hispânica». E poderíamos nós corrigir, considerando a epígrafe de Moura, «às inscrições hispânicas».

Agripina faleceu no ano 33. Ora, se a inscrição de Mentesa - e, por extensão, a de Moura — são do ano 37, que facto terá, então, acontecido para que a memória de Agripina seja recordada em homenagem póstuma?

A pergunta leva-nos, por conseguinte, à segunda questão acima colocada.

Agripina desposou Germânico e foi ela quem trouxe até Brindisi as cinzas de seu marido, morto, em circuntâncias pouco claras, durante a campanha da Síria. Disse-se que fora Tibério o instigador, directo ou indirecto, dessa morte e por isso se compreende que as suas exéquias, apesar do que oficialmente as determinações da Tabula Siarensis pareceriam dar a entender, tenham sido sem oração fúnebre nem grandes pompas: «Não houve 
efígie do morto sobre o catafalco, nem imagines, nem elogia» (Arce 1988, 48).

Nestas circunstancias, qual a atitude assumida por Caligula?

Escreve Suetónio, no capítulo $\mathrm{X}$ da vida deste imperador (p. 157 da citada edição portuguesa de 1979): «Acompanhou ainda o pai na expedição à Síria. No regresso conservou-se, primeiro, em casa da mãe; depois que esta foi exilada, em casa da bisavó»». Referem-se depois, nesse mesmo capítulo, «as ciladas que lhe armaram». $\mathrm{Na}$ verdade, Tibério acabara por desterrar Agripina para a ilha Pandatária, onde ela viria a falecer. E Caligula, que assistira a todos os conluios do imperador, não seria decerto também persona grata e não nutria por Tibério qualquer afeição.

Assim se explica que, ao subir ao trono imperial, logo após ter feito o elogio fúnebre oficial de Tibério, se tenha dado «pressa em ir a Pandatária e a Pôncia, apesar do mau tempo, transferir as cinzas da mãe e do irmão [...]. Acercou-se daquelas cinzas com respeito e foi ele próprio quem as encerrou nas suas urnas. Não foi menor a pompa com que as tr ansportou para Òstia, a bordo de uma birreme à popa da qual flutuava um estandarte, e de Òstia, pelo Tibre, até Roma, onde foram recebidas pelas mais distintas personalidades da ordem equestre, depostas, em pleno dia e no meio da multidão, sobre dois andores, o levadas para o Mausoléu de Augusto. Determinou que se fizessem em sua honra sacrifícios públicos anuais, e em honra de sua mãe jogos de circo, onde a sua imagem devia comparecer com toda a sumptuosidade em cima de um carro. Em memória do pai deu ao mês de Setembro o nome de Germânico» (capítulo XV da obra citada, p. 160 da edição portuguesa).

Compreende-se, pois, que todo este ambiente de exaltação familiar que vai ao encontro da esperança que Germânico representara («Roma está salva, a pátria está salva, Germânico está salvo», ibidem, VI, p. 155) e que Caligula poderá, enfim, retomar — tenha tido repercussão na Hispânia. É, de resto, neste clima de confiança renovada que se deve situar - como, aliás, R. Etienne bem assinalou $(1974,436)$ - o juramento prestado pelos Aricienses (de Aritium Vetus, provavelmente Alvega, no concelho de Abrantes - IRCP 647), escassos cinquenta e dois dias passados após a morte de Tibério. E é também nesse âmbito que deve ser encarada doravante a homenagem da civitas Aruccitana à mãe do imperador. 
Aliás, Caligula apresenta-se como um novo Augusto - o juramento dos Aricienses invoca Júpiter Óptimo Máximo e o divino Augusto... — e, daí, a circunstância de sua mãe ser designada «Augusti nepos», neta do fundador do Império $\left(^{7}\right)$.

E não será apenas a epigrafía que servirá os intuitos imperiais : a amoedação do inicio do seu reinado terá como finalidade primordial «reabilitar os seus parentes mortos que pertenciam à casa de Germânico» (Étienne, 1974, 437). Aí se incluem as já referidas moedas de Caesaraugusta dedicadas a Agripina.

Ocorrerá, então, perguntar por que razão se não encontraram mais reflexos dessa política imperial? A explicação já foi dada por R. Étienne (1974, 438-439): é que bem depressa o imperador decidiu voltar as costas aos seus parentes, vivos ou mortos (cf. o capítulo XXIII de Suetónio, p. 165 da citada edição), deixando-se seduzir por uma certa experiência de teocracia à moda egípcia - que acabaria por lhe acarretar a morte.

Em conclusão: pela sua importância como reflexo ímpar de um curto período da história imperial romana, é, pois, o cipo guardado no museu de Moura um monumento de referência obrigatória.

(7) Nos primeiros tempos do seu reinado, Caligula dará ordens explícitas quanto à sua identificação nos monumentos, de forma que fique bem clara a sua ligação familiar ao fundador do Império: uma leitura dos títulos reunidos na p. 1097 do CIL II referentes aps testemunhos epigráficos peninsulares mostra como houve o cuidado de o assinalai como «neto de Tibério, bisneto do divino Augusto, trineto do divino Júlio»... 


\section{BIBLIOGRAFIA}

Arge (Javier), La tabula Siarensis y los funerales imperiales (II), «Estudios sobre la Tabula Siarensis», Madrid, 1988, 43-50.

GIL II — Vide Hü BNeR.

EE - Vide HÜ BNER 1899.

Étienne (Robert), Le culte impérial dans la Péninsule Ibérique d'Auguste à Dioclétien, Paris, 1958 (reimpr. 1974).

González (Julián), Divinidades prerromanas en Andalucia, comunicação apresentada ao Colóquio Internacional de Epigiafia «Culto e Sociedade no Ocidente», realizado em Tarragona, de 6 a 8 de Dezembro de 1988 [a publicar nas respectivas actas ].

HübNeR (E.), Corpus Inscriptionum Latinarum, II, Berlim, 1869 e 1892 (Suplemento) (= CIL li).

HübNeR (E ), Additamenta nova ad corporis volumen II, «Ephemeris Epigraphica», VIII, 1899, 351-528.

ILER-Vide VIVES.

IRCP = ENCARNAÇão (José d') Inscrições romanas do conventus Pacensis. Coimbra, 1984.

Lima (José Fragoso de), Monografia arqueológica do concelho de Moura, Edição da Câmara Municipal de Moura, 1988.

Morales (A.), Antigüedades de las ciudades de Espana... ${ }^{1} 1575$ (Alcalá), 21791-2 (Madrid).

RESENDE (André de), De antiquitatibus Lusitaniae..., *1593 (Évora), ${ }^{2} 1790$ (Coimbra).

Suetónio, Os Doze Césares. Editorial Presença, Lisboa, ${ }^{3} 1979$. [Tradução de João Gaspar Simões].

Trillmich (W), Ein Kopffragment in Mérida und die Bildnisse der Agrippina Minor aus den Hispanischen Provinzen, «Homenaje a Saenz de Buruaga», Badajoz, 1982,109-126.

Vives (J.), Inscripciones latinas de la España romana, Barcelona, 1971 e 1972 (índices) (= ILER). 
(Página deixada propositadamente em branco) 
Est. I

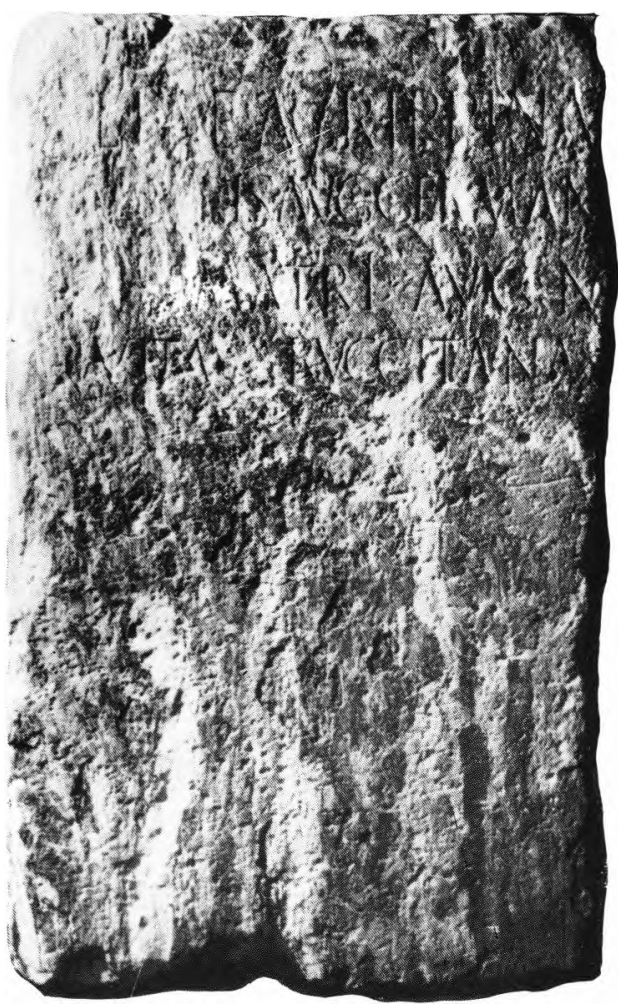

A face dianteira do cipo 
EST. II

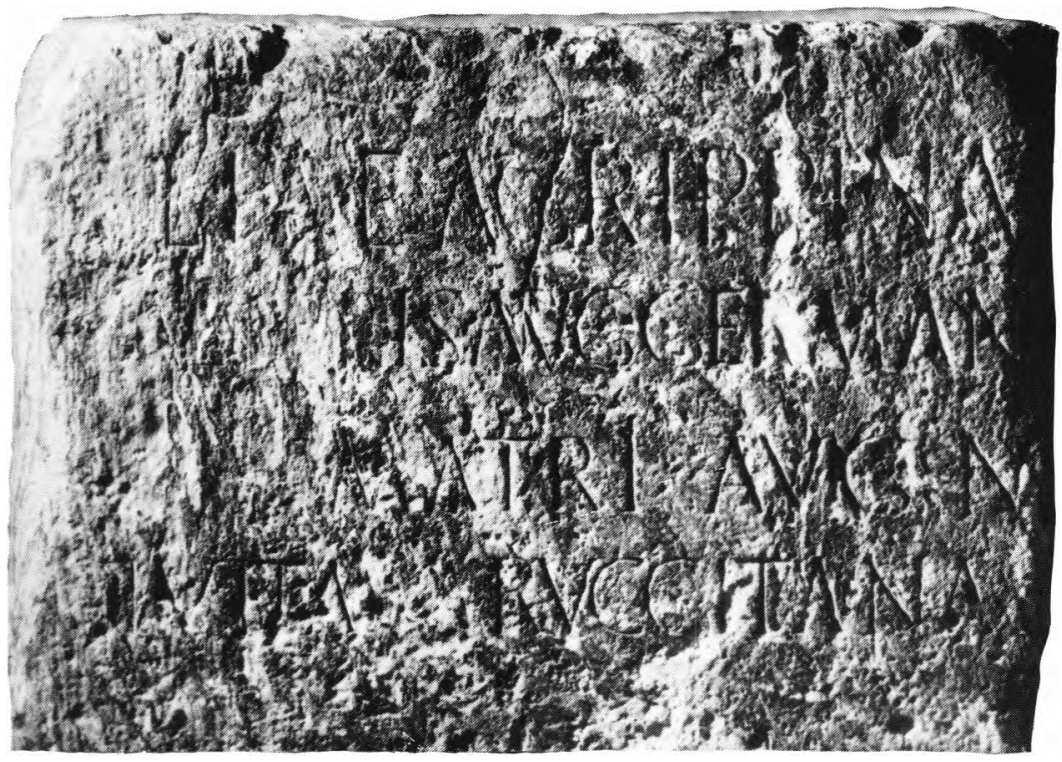

A dedicatória 
EST. Ill

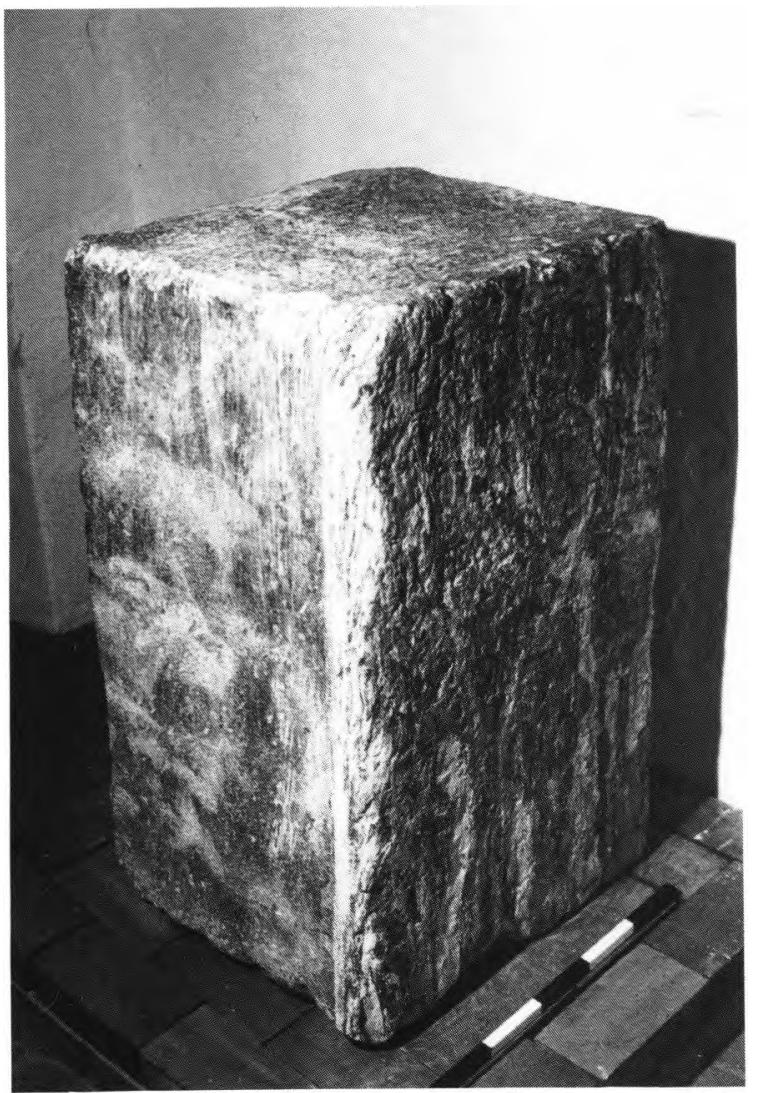

O cipo na sua totalidade 